\title{
Detrimental orofacial manifestations of dengue and dengue hemorrhagic fever- clinical case series, review of the causes, complications, and vaccine strategies
}

SADJ September 2021, Vol. 76 No. 8 p457 - p464

SR Dutta ${ }^{1}$, P Singh ${ }^{2}$

\section{ABSTRACT}

\section{Introduction}

It is estimated that there are about $10 \%$ of cases that involve oral mucosa in patients with dengue hemorrhagic fever (HF), and even less number of cases in dengue fever (DF) has been reported. This leads to a lack of future investigation.

\section{Aims and objectives}

This review intends to enhance the understanding of the epidemiology, clinical features involving the oral manifestations, and treatment of dengue disease.

\section{Design and Methods}

Several search engines, including PubMed, World Health Organization (WHO), and Pan American Health Organization $(\mathrm{PAHO})$ websites were utilized for the literature search using the terms dengue and dengue shock syndrome.

\section{Results}

Dengue is a major arthropod-borne viral disease of humans. Its presentation is protean and varies from an undifferentiated viral syndrome to viral HF and severe shock. The early diagnosis of the oral manifestations, hemorrhagic, or mucocutaneous, may lead to timely clinical evaluation of the patient with signs and symptoms suggestive of dengue viral infection.

\section{Conclusion}

The specific therapy for dengue infections is still undiscovered. Proper care, including vector control and prevention of mosquito bites, may be beneficial. However,

\footnotetext{
Author affiliations:

1. Dr. Shubha Ranjan Dutta: ORCID - 0000-0003-3643-1200

2. Dr. Purnima Sing: ORCID - 0000-0002-0675-9128
}

Corresponding author:

Dr Purnima Singh: purnimasingh99@gmail.com

Author contributions:

1. Dr. Shubha Ranjan Dutta: Collection of data (case reports), analysis of the data, drafting of the manuscript

2. Dr. Purnima Sing: Analysis of the data, its organization, drafting the manuscript, and revising the manuscript the role of dental professionals and general practitioners is important in identifying the oral manifestations of dengue viral infection and providing specific diagnosis and effective treatment to the patients.

\section{Keywords}

Dengue, dengue hemorrhagic fever, oral manifestations, dengue vaccines

\section{INTRODUCTION}

Dengue disease is an acute disease caused by four closely related serotypes of dengue virus from the Flaviviridae family, namely DENV-1, DENV-2, DENV-3, and DENV-4. The four variants are indistinguishable clinically. The viruses are composed of one strand of ribonucleic acid (RNA), which is within the same genus, thanks to the yellow jack and West Nile viruses. Dengue disease is the foremost prevalent mosquito-borne viral disease in humans, occurring in tropical and subtropical countries of the globe where over 2.5 billion people are in peril of infection. ${ }^{1}$ The World Health Organization (WHO) has estimated 50 million cases of dengue and the spread of another hundred thousands of cases of dengue viral hemorrhagic fevers (VHF) occuring annually, that stimulate the epidemic activity. ${ }^{2}$ It is estimated that about 1.8 billion people die from dengue in the WHO member states of Western Pacific and SouthEast Asia. ${ }^{3}$ Therefore, the early diagnosis of the dengue virus infection in the febrile stage is critical for appropriate management. The availability of scientific literature that reports on the oral manifestations of dengue fever (DF) are scanty as the signs and symptoms of the affected patients usually get unnoticed or misinterpreted with other conditions, most likely leukemia, hemophilia, thrombocytopenia by the dental professionals. WHO included gingival bleeding, a common oral manifestation of DF as the nonspecific finding of the disease. ${ }^{4}$ This review focuses on the identification of the predictive markers of oral and clinical findings within the acute stage of dengue infection. Dengue VHF (DHF) was first documented in 1953 in Manila, the Philippines. ${ }^{5}$ In humans, the manifestations of dengue infection vary from relatively mild, nonspecific viral syndrome mentioned as DF to severe hemorrhagic disease and death. The severe hemorrhagic like disease known as DHF and 
dengue shock syndrome (DSS), is the usual explanation for hospitalization and death among children in Asia. ${ }^{6}$

\section{Epidemiology}

About 500,000 to 1,000,000 individuals' worldwide contract DF/ DHF annually, making it the foremost common arthropod-borne disease on earth. ${ }^{7} \mathrm{WHO}$ also has an internet-based system for global surveillance of DF/ DHF known as DengueNet to monitor and guide dengue/DHF prevention and control programs.

\section{Pathophysiology and Oral Manifestations}

The life-span of DF within the mosquito is $8-12$ days followed by a further 3-14 days within the human host. This is often followed by clinical disease lasting 3-7 days. The virus is passed from mature female mosquitoes to their offspring, and an infected mosquito is infectious throughout its lifespan. The amount of clinical dengue infection ranges from asymptomatic infection to critically ill patients with hemorrhage and shock. Case definitions are described in TABLE I.

Individuals with DSS develop antibodies and lifelong immunity to the variant that they contracted and a transient immunity to all or any four of the variants. Only after a second, third, or fourth infection (i.e., with a special variant) is contracted, is it likely to develop a clinical case of hemorrhagic disease. Transplacental transfer of maternal antibodies can put an infant in peril for DHF. ${ }^{8}$

The oral cavity is considered the gateway and the site of manifestation of a wide range of systemic diseases. Therefore, the identification of oral manifestations of dengue becomes of utmost necessity to establish the early diagnosis of this pathology. Oral manifestations are commonly associated with DHF, and infrequently in cases of classic DF. These include vesicles on the lips and palate, lip crustings, and blisters in different areas of the mouth, gingival bleeding, erythema, oral candidiasis, osteonecrosis of the dentoalveolar structure, lingual hematoma, osteonecrosis of the jaw, and difficulty in swallowing. ${ }^{9,10}$ In such a scenario the role of dental professionals, especially general practitioners, becomes most important to identify these problems and guide the patient for effective medical care and treatment.

The general pathologic findings ${ }^{11}$ include:

- Depression of megakaryocytes and other hemopoietic cells within the bone marrow.

- Active proliferation of lymph nodes and spleen, and lymphocytolysis in germinal centers.

- Focal mid-zonal necrosis and fatty changes within the liver.
- Occasional glomerulonephritis (due to immune complex deposition).

\section{Case Presentations}

A few clinical case reports obtained from patients visiting the out-patient department (OPD) clinic in our Institution are presented below to address, in a specific way, oral manifestations associated with or related to DF. These reports are presented after written consents were obtained from the patients.

\section{CASE REPORT 1}

A moderately aged male patient ( 55-65 years, not accurately determined by the patient) visited the hospital for an ulcer in his mouth, pain-free gum bleeding, and trouble in gulping. He additionally gave a history of fever for several weeks and body temperature ranging between $110^{\circ} \mathrm{F}$ and $120^{\circ} \mathrm{F}$. Ulcers at first had begun in the right mandibular posterior buccal mucosa and afterward included the junction of hard and soft palate [Figure 1A], tongue [Figure 1B]. He also had several tiny red spots on his face [Figure 1C] for more than one month. History uncovered that he had joint pain from the past few days with a history of fever. On clinical assessment, petechiae were observed in the upper face and neck. He had an axillary temperature of about $125^{\circ} \mathrm{F}$. Respective submandibular lymphadenopathy was obvious. The intraoral assessment revealed raised hemorrhagic plaques on the right posterior buccal mucosa just as on the dorsum of the tongue and floor of the mouth [Figure 1D]. The hemorrhagic plaques were encircled by the erosive mucosa, and the outside of the hemorrhagic plaques was sporadic. At the intersection of the hard and soft palate, a diffuse erosion of 4 $\times 4 \mathrm{~cm}$ was available. The tonsils on both right and left sides were extended, erythematous and aggravated. The patient had xerostomia and the tongue had all being coated with plaques. A tourniquet test was performed and around 1015 petechiae $/ 2.5 \mathrm{~cm}^{2}$ were observed. The patient was then exposed to a progression of hematological and biochemical examinations. Platelet count was 45000 cells $/ \mathrm{mm}^{3}$, absolute leukocyte counts 3500 cells $/ \mathrm{mm}^{3}$, serum albumin $2.8 \mathrm{~g} / \mathrm{dl}$, hemoglobin $9 \mathrm{gm} / \mathrm{dl}$, and ESR 49mm/hr., INR> 1.5, Bleeding time 8 minutes were noted.

With the above outcomes, a temporary determination of DHF was made. To confirm further, immunoglobulin M (IgM) was identified by an immunizer catch protein connected enzyme-linked immunosorbent assay (ELISA; 7 days after the beginning of indications).

\section{CASE REPORT 2}

A 49 year old female patient visited the clinic for a painless therapy of blister in her mouth, bleeding from the gums and

\begin{tabular}{|c|c|c|c|}
\hline & Type & Primary symptom & Secondary symptom \\
\hline A. & $\begin{array}{l}\text { Asymptomatic or } \\
\text { mild infection }\end{array}$ & Very common and few or no symptoms besides fever & \\
\hline B. & DF & Fever and two or more of the secondary symptoms & $\begin{array}{l}\text { Retro orbital/ocular pain, headache, rash, myalgia, arthralgia, } \\
\text { leukopenia, hemorrhagic symptoms that do not meet the } \\
\text { definition of DHF }\end{array}$ \\
\hline C. & DHF & All symptoms of DF plus secondary symptoms & $\begin{array}{l}\text { Thrombocytopenia (less than } 100,000 \text { cells per microliter of } \\
\text { blood), Evidence of plasma leakage manifested by hemocon- } \\
\text { centration (increase in hematocrit }>20 \% \text { of normal for age or a } \\
\text { decrease }<20 \% \text { after rehydration) or pleural effusion, ascites, or } \\
\text { hypo-proteinemia. }\end{array}$ \\
\hline D. & DSS & All symptoms of DHF plus secondary symptoms & $\begin{array}{l}\text { Signs of shock, including rapid pulse, narrow pulse pressure and, } \\
\text { most importantly, poor organ perfusion }\end{array}$ \\
\hline
\end{tabular}



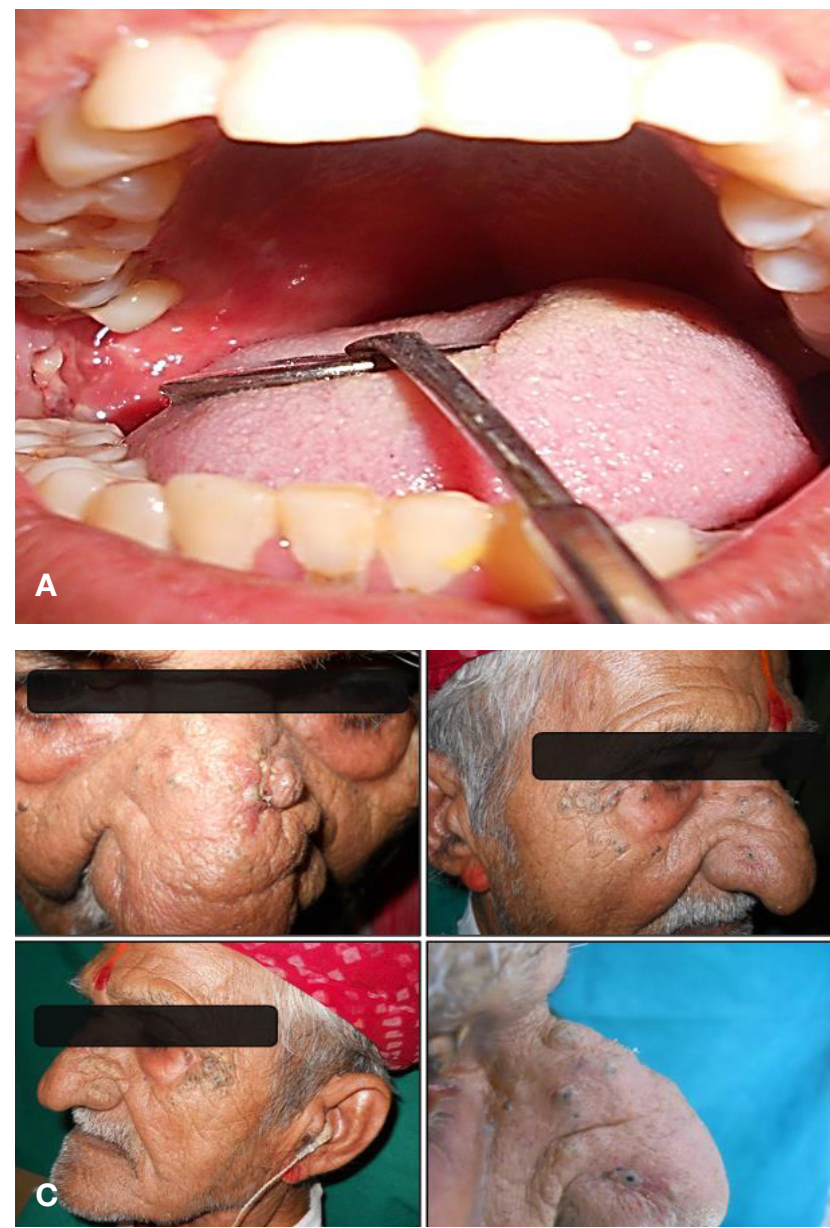

Figure 1. Orofacial manifestations of dengue for Case 1.

alveolar mucosa on the left posterior back of the jaw [Figure 2A] for the past one month and she had trouble swallowing for as far back as 15 days. She was accounted for a history of high-grade fever for over a few weeks, stomach pain, and occasional nose and gum bleeding. Rankles at first were present on the left half of maxillary alveolar mucosa followed by its appearance on the upper right mucosa. Bluish-red vessels were observed prominently for 4-5 days in the lower appendages on gripping. There were continuous joint aches from the hour of the beginning of the fever. On clinical assessment, petechiae were observed everywhere on the body including the upper and lower appendages except the palms and soles, lower face, [Figures 2B] and neck. The axillary temperature of $103^{\circ} \mathrm{F}$ was noted. On palpation, respective submandibular lymphadenopathy was apparent. The intraoral assessment revealed the appearance of common ulcerative and hemorrhagic sores on both sides of the lower jaw, starting from cuspid to molar region. Petechiae were additionally present on the extraoral lower face and intraoral right lower posterior premolar and molar regions. At the intersection of the hard and soft palate and mostly on the hard palate, on both sides, little blood-filled vessels were prominent [Figure 2C]. On the right posterior buccal mucosa strip band of dark blue hemorrhagic band observed [Figure 2D]. A tourniquet test was performed and around 15-30 petechiae/2.5 $\mathrm{cm}^{2}$ were observed. The patient was then exposed to significant hematological and biochemical examinations to build up the analysis. Thrombocytopenia (45000 cells $\left./ \mathrm{mm}^{3}\right)$, absolute leukocyte counts $\left(3300\right.$ cells $\left./ \mathrm{mm}^{3}\right)$, lymphocyte check (9\%), serum albumin $(2.9 \mathrm{gm} / \mathrm{dl})$, hemoglobin (10 gm/dl), and ESR $(45 \mathrm{~mm} / \mathrm{hr})$, INR (> 1.5), Bleeding time (9.15 minutes) were recorded. The testing of dengue virus IgM by a capture
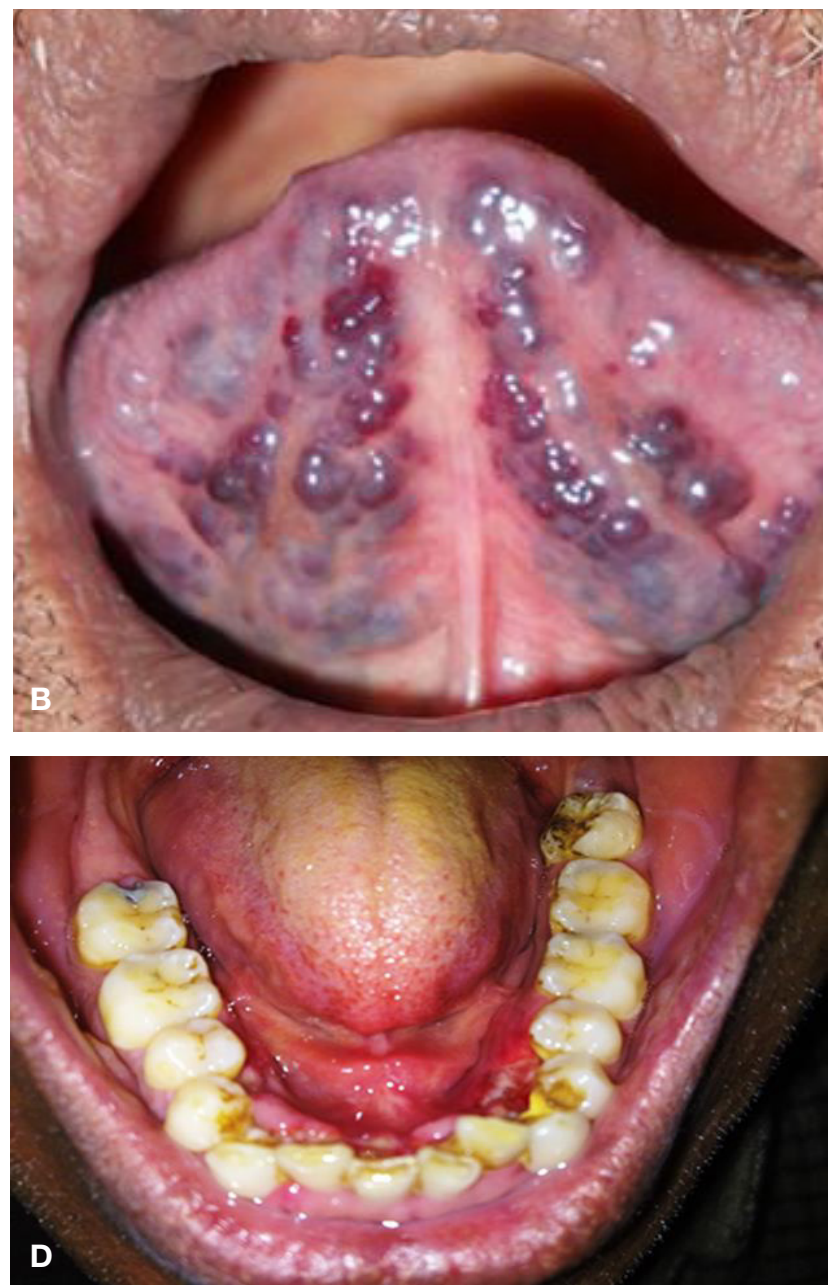

ELISA (MAC-ELISA) is very sensitive and can be performed at least five days after the beginning of fever for confirmatory diagnosis.

\section{CASE REPORT 3}

A 25-year-old male patient was reported with painless blood clots on the lower front region (cuspid to cuspid) of the jaws [Figure 3A] and non-healing ulcers on the lower lip [Figure 3B] and right posterior lower back region on the jaw [Figure $3 \mathrm{C}$ ]. The patient was determined to have DF and presented signs and manifestations related to high fever, muscle pain, and rash. Serologic tests uncovered the immunoglobulins (IgM) and (IgG) for dengue antigens. Under clinical diagnosis, the patient was taking acetaminophen $(500 \mathrm{mg}$ ) four times each day and oral hydration. White cell count was 2500 cells $/ \mathrm{mm}^{3}$ (out of these of these $1155 / \mathrm{mm}^{3}$ were neutrophils. Petachiae, bleeding gums, ulcer, dryness of the mouth were the intraoral manifestations. His platelet count was $59,000 / \mathrm{mm}^{3}$, prothrombin time $>30$ seconds. The intraoral assessment uncovered a few white plaques with ulcerative spot situated on the lower lip mucosa. The patient had a history of headache, orbital pain, hematemesis, and hematochezia. Detecting viral genomic sequences with real-time reverse transcriptionpolymerase chain reaction (rRT-PCR) or dengue nonstructural protein 1 (NS1) antigen by immunoassay can confirm the presence of dengue in patients with a viable clinical history.

\section{Clinical spectrum}

The presentation of the oral manifestations in the above case reports suggests that a thorough evaluation of the oral findings in cases of dengue infection is extremely important, though such reports in the literature are rare. Therefore, it is up 
to the dentists and otorhinolaryngologists to be informed about the various oral manifestations of the disease so that proper diagnosis and treatment can be provided to the patients.

The spectrum of clinical manifestations ${ }^{12,13}$ is shown in Figure 4. Many of the infections that occur in children are asymptomatic, while they are mostly symptomatic in adults. The clinical features ${ }^{12,14}$ and the laboratory investigation ${ }^{11,15}$ for the diagnosis of DHF are enlisted in TABLE II.

\section{Management}

The following steps are necessary for the management of the disease:

1. Hospitalization could be necessary when significant dehydration ( $>10 \%$ of normal body weight) has occurred.
Other signs of great dehydration are highlighted.

2. One should avoid NSAIDs/aspirin.

3. Unless it is indicated, blood transfusion/IV fluids should be avoided.

4. Steroids and antibiotics should be avoided.

5. Rapid changes within the speed of fluid infusion should be avoided.

6. The insertion of a nasogastric tube to figure out concealed bleeding or lavage to stop bleeding are not recommended.

7. If present, acidosis should be corrected.

As hemorrhage is the hallmark of dengue, it is warranted that dentists are aware of the complications of performing dental procedures in patients suffering from DF/DHF. It becomes equally important to know the correct medical histo-

\section{TABLE II: Criteria for diagnosis of DHF Clinical features \\ 1. Pyrexia- sudden, often of high grade, lasts for 2-7 days \\ 2. Hemorrhagic manifestations include at least one of the following: \\ - $\quad$ Petechiae, purpura, ecchymosis \\ - Epistaxis, gum bleeding, bleeding from the lining mucosa, GIT, or injection site \\ - Hematemesis and/or \\ - A positive tourniquet test: a sphygmoma- nometer cuff is inflated on the arm to point midway between systolic and diastolic pressures for five minutes. A positive test is alleged when $>20$ petechiae appear during a $2.5 \mathrm{~cm}$ square (or $3 \mathrm{~cm}$ diameter circle) on the skin surface on the forearm. Patients in shock usually test positive if it is performed after recovery from shock. The test could even be negative or only mildly positive $(>10$ petechiae/2.5 sq. $\mathrm{cm}$ ) during the phase of profound shock.}

3. Hepatomegaly. Formation of degradation products (FDPs).

- Thrombocytopenia.

- Rising hematocrit.

- Metabolic acidosis.

- Urine mild albuminuria

\section{Laboratory investigations}

(A) Virus isolation- The virus should be sought from serum obtained during the febrile phase of the illness.

(B) Serology- Serologic diagnosis is achieved by demonstrating a rise in hemagglutination inhibition, immune reaction, or neutralizing antibody titers inappropriately timed paired sera drawn 7-14 days apart. Samples are collected as follows:

S1 (acute serum) - soon after hospitalization

S2 (convalescent serum) - within 10-14 days before being discharged from the hospital

S3 (late convalescent serum) - within 14-21 days after the onset of the disease

Hemagglutination inhibition assays:

This is one of the WHO-recommended reference tests for dengue virus infections. The disadvantages of these tests are:

- $\quad$ Time consuming

- $\quad$ Cannot identify specific serotypes

- $\quad$ Cross-reaction with other related flaviviruses, e.g., yellow jack, West Nile fever, Japanese encephalitis, etc

ELISA

(i) The IgM antibody - Capture ELISA (MAC-ELISA) is particularly useful in the diagnosis of recent infection. By two days following defervescence, patients with primary or secondary infections have detectable lgM antibodies. However, the antibodies wane rapidly and after 2-3 months, most patients are seronegative. Therefore, tests on one serum sample may indicate a recent infection. However, the lgM antibodies are relatively specific for dengue, and they do not distinguish between the numerous serotypes. The rising titer of lgM antibodies is much more specific.

(ii) IgG ELISA has results and interpretations like the hemagglutination inhibition assay.

\section{Commercial dengue blot assay:}

It is a rapid diagnostic assay, which is as sensitive as hemagglutination inhibition assay in diagnosing a secondary dengue infection but not so just in case of primary infection.

Newer diagnostic techniques:

1. Reverse transcriptase-polymerase chain reaction (RTPCR): detection of viral RNA

2. Hybridization probe: Identification of viral nucleic acids with the assistance of hybridization probes

3. Immuno-cytochemical methods: Use of enzyme conjugates, like peroxidases and phosphatases in conjugation with either polyclonal or monoclonal antibodies to detect dengue virus antigen

\section{Other associated laboratory findings are:}

- $\quad$ WBC count - WBC count could also be normal, but leucopenia is common. Neutrophils decrease towards the top of the febrile phase. A relative lymphocytosis with quite $15 \%$ atypical lymphocytes is common at the top of the febrile phase (critical stage) and early shock stage.

- Hypoproteinemia

- Mildly elevated AST and BUN

- $\quad$ Evidence for DIC: Prothrombin time (PT) and activated partial thromboplastin time (aPTT) with decreased serum fibrinogen and increased Fibrin 

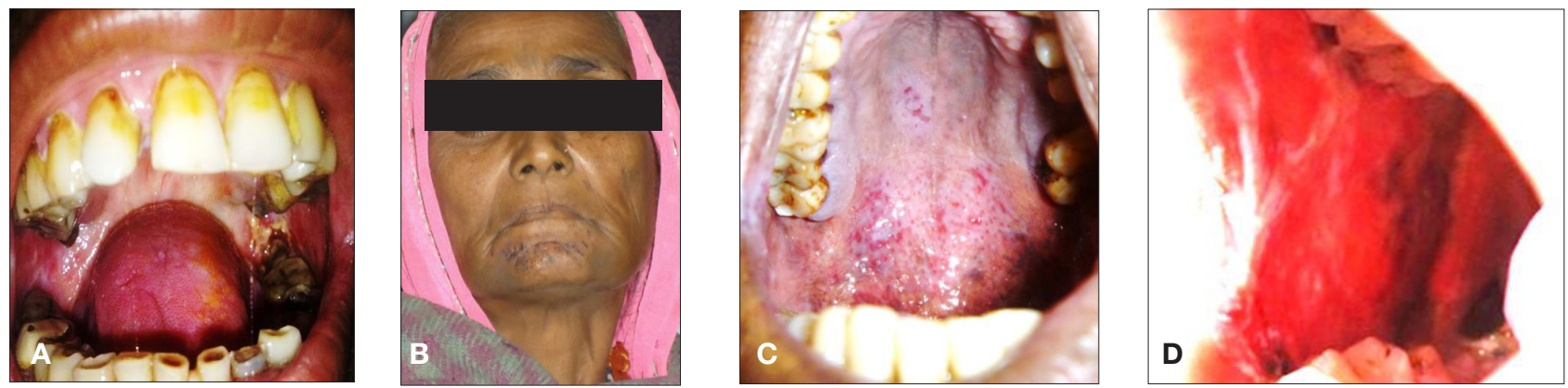

Figure 2. Orofacial manifestations of dengue for Case 2.

ry and suggest appropriate treatment. Besides, the nature of the disease should be considered, and care should be taken to prescribe medicines. These patients should avoid the use of non-essential drugs, especially anti-inflammatories, antibiotics, and other drugs that show renal, hepatic, or hematological toxicity.

The signs of recovery, criteria for discharging patients, factors affecting the prognosis of dengue, and the measures for prevention and control of $\mathrm{DHF}^{14}$ outbreak are described in TABLE III.

\section{Current progress in dengue vaccines}

The development or trial of several vaccines is underway. This includes live attenuated, live chimeric, and inactivated virus vaccines, as well as live recombinant, DNA, and subunit vaccines. ${ }^{16}$ However, there is no licensed dengue vaccine yet. The live attenuated virus vaccines and live chimeric virus vaccines are being evaluated clinically. The opposite vaccine candidates are evaluated in preclinical animal models or are being prepared for clinical trials. For dengue vaccines to be safe and efficient, it is important to consider the immuno- pathogenic complications like antibody-mediated enhancement and autoimmunity.

Disease Prevention Programs: For epidemic prediction, health authorities have to be prepared to accurately monitor dengue virus transmission in a community and provide information at any time point on the site of transmission (Figure 5), virus serotypes causing the infection, and the clinical manifestations that are claimed to be due to dengue infection. ${ }^{17,}{ }^{18}$ Any release of information should be in consultation with infectious-disease physicians. All patients with any hemorrhagic manifestation; on admission diagnosis of viral encephalitis, aseptic meningitis, or meningococcal shock; and/or a fatal outcome following a viral prodrome should be considered. ${ }^{19}$ This proactive television is meant to watch disease activity during the inter-epidemic period before epidemic transmission. Individually, the three components are not sensitive enough to supply effective early warning, but when used collectively, they are visiting often accurately predict epidemic activity. ${ }^{17}$

Mosquito control - Controlling the mosquito vector, Aedes aegypti, in and around the home, where most transmission

TABLE III: Signs of recovery, criteria for discharging patients, factors affecting the prognosis of dengue, and the measures for prevention and control of DHF outbreak

\begin{tabular}{|c|c|c|c|}
\hline Signs of recovery & $\begin{array}{l}\text { Criteria for discharg- } \\
\text { ing patients }\end{array}$ & $\begin{array}{l}\text { Factors affecting the prognosis of } \\
\text { dengue }\end{array}$ & Measures for prevention and control of DHF outbreak \\
\hline $\begin{array}{l}\text { Stable pulse, sign, and } \\
\text { rate of respiration }\end{array}$ & $\begin{array}{l}\text { Absence of fever for } \\
\text { a minimum of } 24 \mathrm{hr} \\
\text { without the use of } \\
\text { antipyretics }\end{array}$ & $\begin{array}{l}\text { The presence of enhancing and non-neu- } \\
\text { tralizing antibodies increases the severity }\end{array}$ & $\begin{array}{l}\text { Vector surveillance and control measures, (e.g. residual } \\
\text { spraying) should be initiated. }\end{array}$ \\
\hline Normal temperature & Return of appetite & $\begin{array}{l}\text { Children below the age of } 12 \text { years are } \\
\text { more susceptible to get DHF/DSS }\end{array}$ & Community participation should be ensured \\
\hline $\begin{array}{l}\text { No evident external/ } \\
\text { internal bleeding }\end{array}$ & $\begin{array}{l}\text { Visible clinical improve- } \\
\text { ment }\end{array}$ & It affects females more than males & $\begin{array}{l}\text { Facilities for case management of patients with } \\
\text { hemorrhagic shock should be assessed }\end{array}$ \\
\hline Return of appetite & Good urine output & It affects Caucasians more than blacks & $\begin{array}{l}\text { Health personnel should be alerted to report the increase/ } \\
\text { clustering of cases }\end{array}$ \\
\hline No vomiting. & $\begin{array}{l}\text { A recovery period of } \\
\text { at least } 3 \text { days from } \\
\text { shock }\end{array}$ & Malnutrition is protective & $\begin{array}{l}\text { Prevention measures for the control of mosquito bites } \\
\text { should be conveyed to the general population: } \\
\text { i. Wearing clothes that cover arms and legs } \\
\text { ii. Using mosquito nets/repellants } \\
\text { iii. Keeping patients shielded from a sting within the acute } \\
\text { phase }\end{array}$ \\
\hline Good urine output & $\begin{array}{l}\text { No respiratory distress } \\
\text { and ascites }\end{array}$ & $\begin{array}{l}\text { The sequence of infection: Serotype } 1 \\
\text { followed by serotype } 2 \text { seems to be more } \\
\text { dangerous than serotype } 4 \text { followed by } \\
\text { serotype } 2\end{array}$ & $\begin{array}{l}\text { Eliminating mosquito-breeding places: } \\
\text { i. Emptying water tanks once hebdomadally } \\
\text { ii. Covering and sealing septic tanks and soak-away pits } \\
\text { iii. Removing rubbish } \\
\text { iv. Removing water from coolers and other places where } \\
\text { water has remained stagnant }\end{array}$ \\
\hline Stable hematocrit & $\begin{array}{l}\text { Increased platelet (> } \\
50,000 / \text { per microliter } \\
\text { of blood) count }\end{array}$ & $\begin{array}{l}\text { Infecting serotype: Type } 2 \text { is more danger- } \\
\text { ous than the other serotypes }\end{array}$ & \\
\hline $\begin{array}{l}\text { Convalescent confluent } \\
\text { petechial rash }\end{array}$ & & & \\
\hline
\end{tabular}



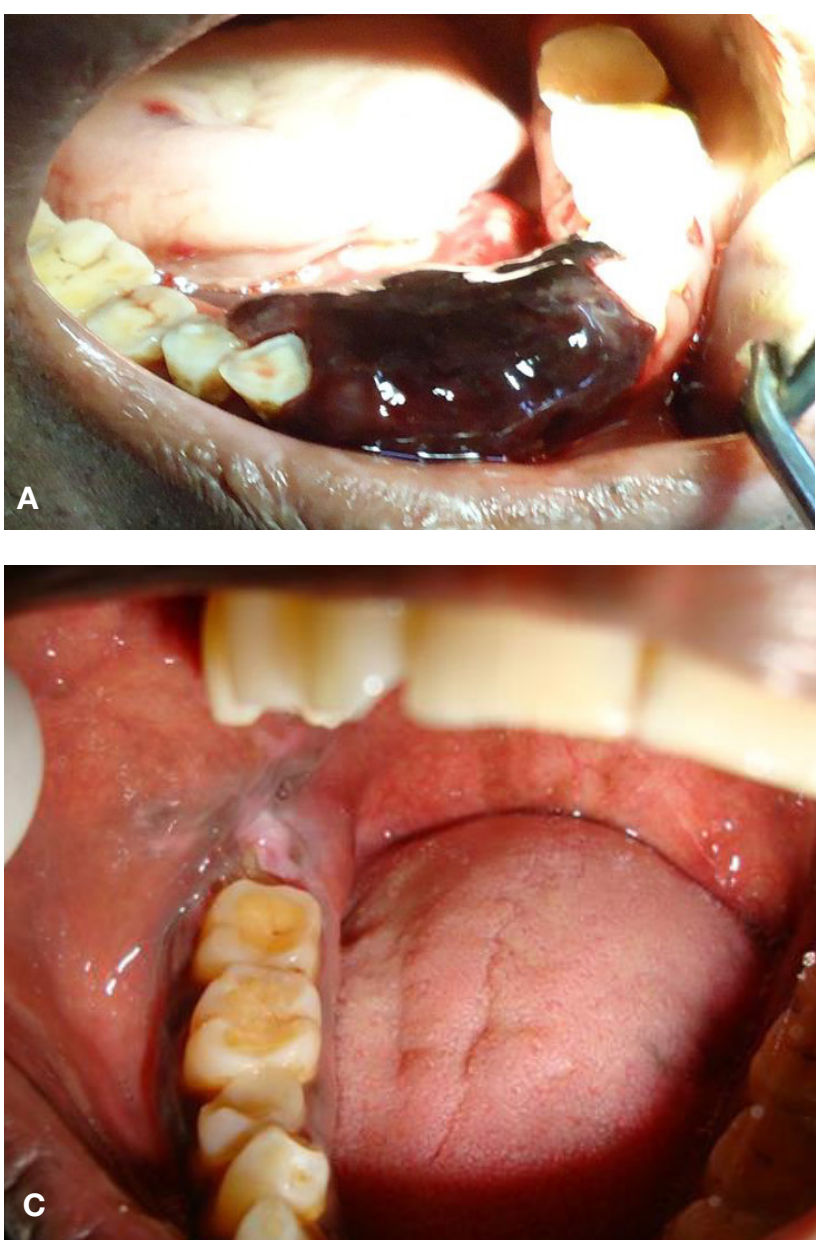

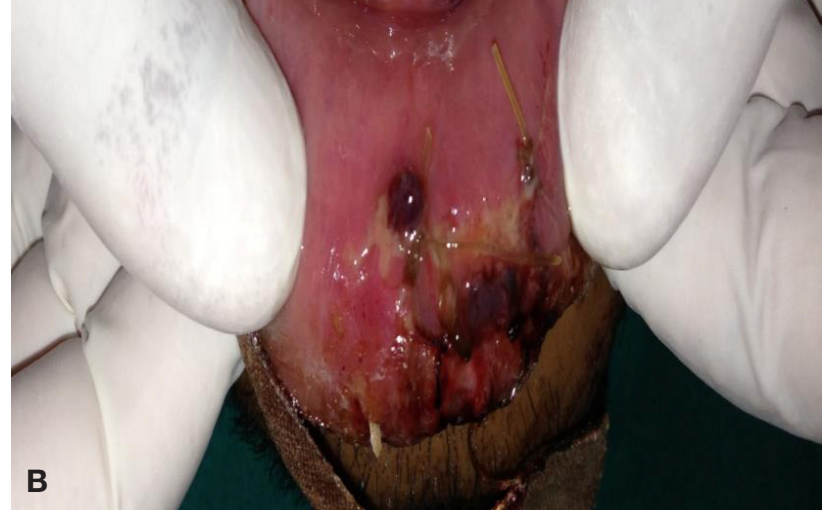

occurs is important for the prevention and control of dengue and DHF. Space sprays with insecticides to kill adult mosquitoes are not usually effective ${ }^{18-20}$ unless they are used indoors. The water-holding containers that function as the larval habitats for Aedes aegypti within the domestic environment should be eliminated or cleaned. ${ }^{18}$, 20, 21 There are two approaches to effectively control Aedes aegypti involving larval source reduction. Within the past, the foremost effective programs have had a vertical, paramilitary organizational structure with an outsized staff and budget. ${ }^{21}$ In recent years, the focus has been placed on communitybased approaches for larval source reduction to supply program sustainability. ${ }^{18}$ The effectiveness of this approach remains unknown. Mosquito control for dengue prevention has recently been reviewed. ${ }^{20}$

Figure 3. Oral manifestations of dengue for Case 3

\section{DENGUE VIRUS INFECTION}

\section{Asymptomatic}

\section{Symptomatic}

Undifferentiated
Fever

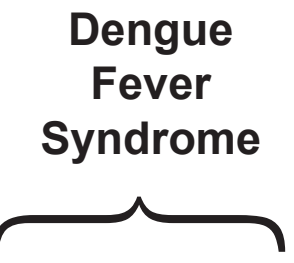

Without

Hemorrhage

With Unusual
Hemorrhage

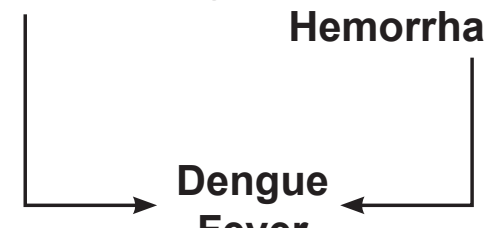

Shock

\section{Dengue Hemorrhagic}

Fever Fever

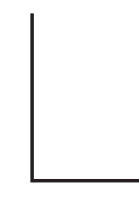

Dengue Hemorrhagic

Fever 


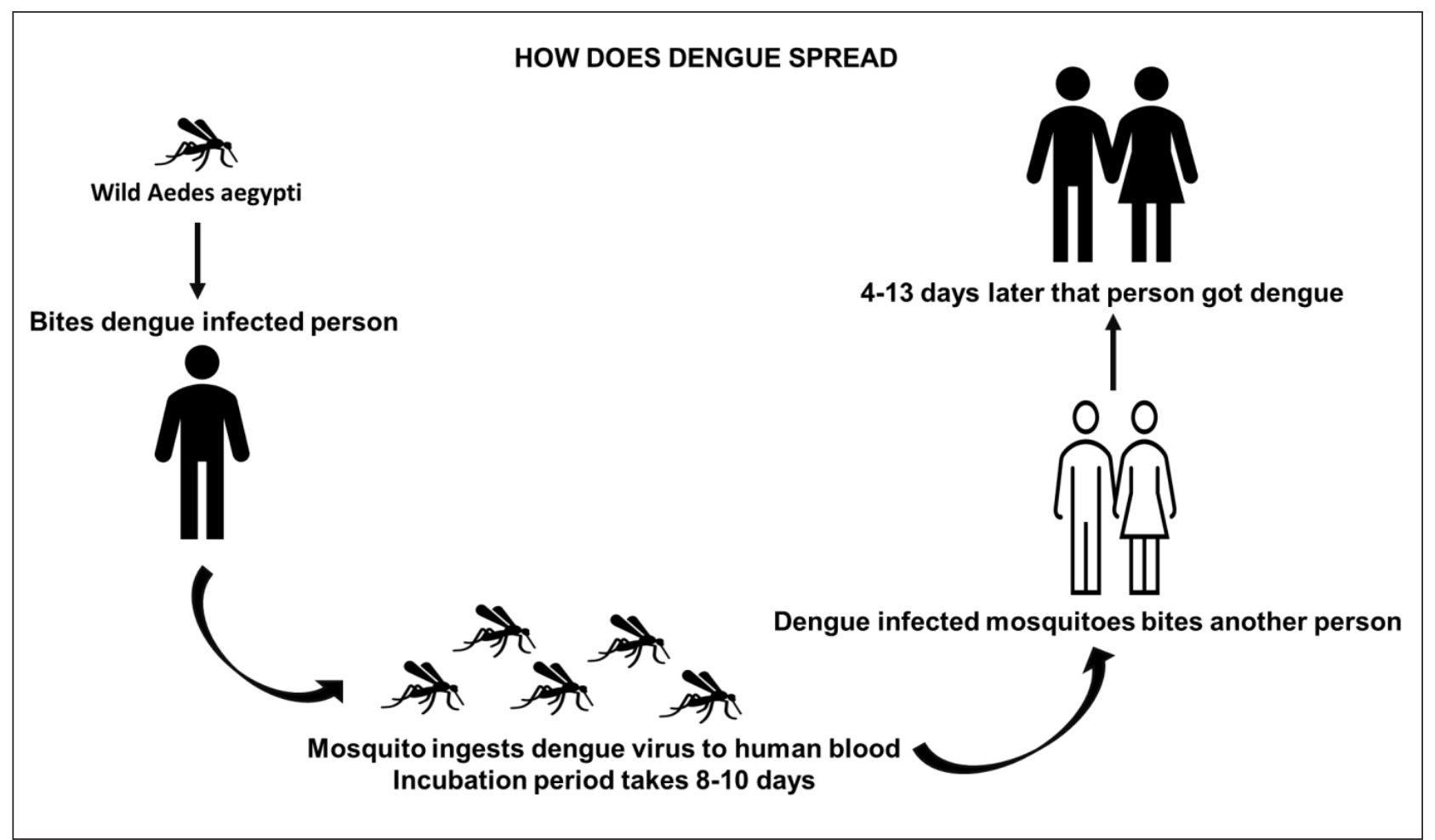

Figure 5: Schematic representation of the mode of spread of dengue virus

\section{Conclusion}

Dengue is a typical self-limiting disease. However, the lack of proper monitoring and adequate volume replacement may cause a fatal outcome. There is an insight into emerging outbreaks of dengue in various states of India. The oral manifestations regarding DF/ DHF are not commonly reported, hence dental professionals should be made aware of the broad range of alterations during dengue viral infections. This review with case presentation highlights the importance of oral lesions due to DF to clinicians of all fields, especially in dengue epidemic or endemic areas. Therefore, it becomes imperative for dental and medical care physicians to acquire updated knowledge about early diagnosis and management guidelines. Moreover, future research with appropriate methodologies focusing on the oral manifestations of DF/ DHF is required to provide a detailed description of the oral changes in the context of dengue infection.

\section{Disclosure}

Nothing to disclose.

\section{References}

1. Halstead SB. Dengue. Lancet 2007; 370:1644-52. DOI: 10.1016/S0140-6736(07)61687-0

2. Mackenzie JS, Gubler DJ, Petersen LR. Emerging flaviviruses: the spread and resurgence of Japanese encephalitis. West Nile and dengue viruses. Nat Med 2004; 10:S98-S109. DOI: 10.1038/nm1144

3. Edelman R. Dengue vaccines approach the finish line. Clinical infectious diseases: an official publication of the Infectious. Dis Soc Am 2007; 45:S56-S60. DOI: $10.1086 / 518148$

4. Fernandes $\mathrm{Cl}$, Perez LE, Perez DE. Uncommon oral manifestations of dengue viral infection. Braz J Otorhinolaryngol 2020; 86:S3-S5. http://dx.doi.org/10.1016/j. bjorl.2016.10.001.

5. Gubler DJ. Dengue and dengue hemorrhagic fever; its history and resurgence as a global public health prob- lem. In: Gubler DJ, Kuno G, eds. Dengue and Dengue Hemorrhagic Fever. London: CAB International, 1997: $1-22$.

6. Halstead SB. Is there an in apparent dengue explosion? Lancet 1999; 353:1100-1. DOI: 10.1016/S01406736(05)76460-6

7. Guerdan B. Dengue Fever/Dengue Hemorrhagic Fever. American Journal of Clinical Medicine 2010; 7:51-53. https://www.aapsus.org/wp-content/uploads/Dengue-Fever-Dengue-Hemorrhagic-Fever.pdf

8. Template for Placing Diseases or Conditions Under National Surveillance, Council of State and Territorial Epidemiologists. Revised 2008, page 12. https://cdn.ymaws. com/www.cste.org/resource/resmgr/PS/09-ID-52.pdf

9. Khan S, Gupta ND, Maheshwari S. Acute gingival bleeding as a complication of dengue hemorrhagic fever. J Indian Soc Periodontol 2013; 17:520-2. DOI: 10.4103/0972-124X.118328

10. Indurkar MS, Sethi R. An unusual case of osteonecrosis of jaw associated with dengue fever and periodontitis. Aust Dent J 2015; 61:113-19. DOI: 10.1111/adj.12308

11. Vaughn DW, Greene S. Dengue and Dengue Hemorrhagic Fever. In: Strickland GJ, eds. Hunter's Tropical Medicine and Emerging Infectious Diseases. Philadelphia: WB. Saunders and Co, 2000: 240-5.

12. Park K. Dengue Syndrome. In: Park K, eds. Textbook of Preventive and Social Medicine. Jabalpur: M/s. Banarsidas Bhanot, 2000; 186-9.

13. WHO. Dengue Hemorrhagic Fever: Diagnosis, treatment, prevention, and control. 2nd ed: Geneva, 1997. https:// www.who.int/csr/resources/publications/dengue/Denguepublication/en/

14. National Institute of Communicable Diseases. Investigation and Control of Outbreaks: Dengue and Dengue hemorrhagic fever, July 1997.

15. Chugh SK, Yadava SK. Dengue hemorrhagic fever. In: Panja M, eds. Medicine Update Proceedings of Scientific Sessions, APICON. Association of Physicians of India, 2001; 315-9. 
https://silo.tips/download/dengue-fever-a-dangerous-foe

16. Murrell S, Wu SC, Butler M. Review of dengue virus and the development of a vaccine. Biotechnol Adv 2011; 29:239-47. 10.1016/j.biotechadv.2010.11.008

17. Gubler DJ, Casta-Velez A. A program for prevention and control of epidemic dengue and dengue hemorrhagic fever in Puerto Rico and the U.S. Virgin Islands. Bull Pan Am Health Org 1991; 25:237-47.

18. Rigau-Perez JG, Gubler DJ. Surveillance for dengue and dengue hemorrhagic fever. In: Gubler DJ, Kono G, eds. Dengue and dengue hemorrhagic fever. London: CAB International, 1997; 405-23.

19. Gubler DJ, Suharyono W, Sumarmo, Wulur H, Jahja E, J Sulianti Saroso. Virological surveillance for dengue haemorrhagic fever in Indonesia using the mosquito inoculation technique. Bulletin of the World Health Organization 1979; 57:931-6. PMID: 43776 PMCID: PMC2395842

20. Gubler DJ. Aedes aegypti and Aedes aegypti -borne disease control in the 1990s: top down or bottom up. Am J Trop Med Hyg 1989; 40: 571-8. DOI: 10.4269/ ajtmh.1989.40.571

21. Newton EAC, Rieter P. A model of the transmission of dengue fever with an evolution of the impact of ultralow volume (ULV) insecticide application on dengue epidemics. Am J Trop Med Hyg 1992; 47:709-20. DOI: 10.4269/ajtmh.1992.47.709

\section{Do the CPD questionnaire on page 501}

The Continuous Professional Development (CPD) section provides for twenty general questions and five ethics questions. The section provides members with a valuable source of CPD points whilst also achieving the objective of CPD, to assure continuing education. The importance of continuing professional development should not be underestimated, it is a career-long obligation for practicing professionals.

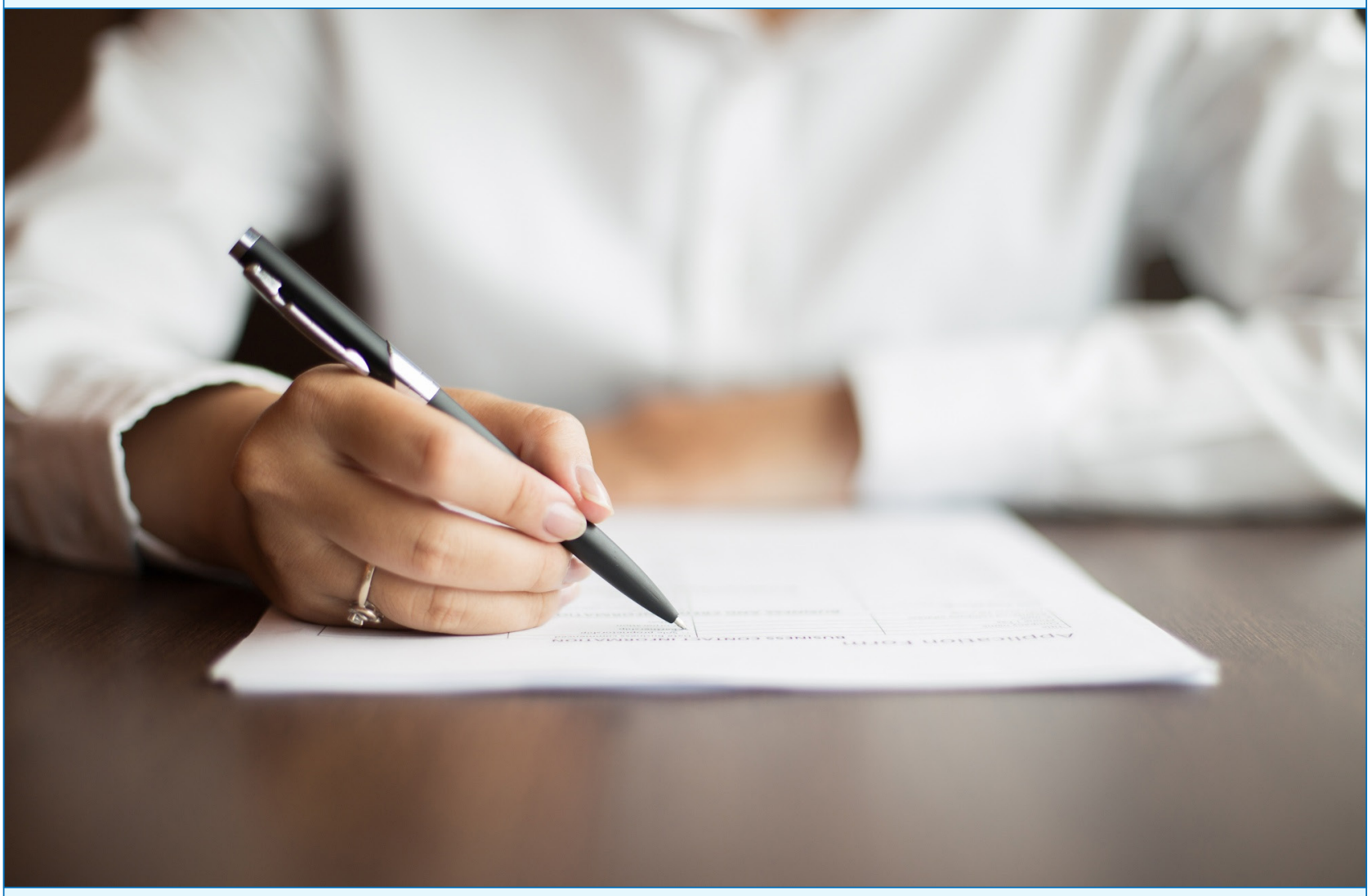

Online CPD in 6 Easy Steps

1 Go to the SADA website www.sada.co.za.

2 Log into the 'member only' section with your unique SADA username and password.

3 Select the CPD navigation tab.

4 Select the questionnaire that you wish to complete.

5 Enter your multiple choice answers. Please note that you have two attempts to obtain at least $70 \%$.

6 View and print your CPD certificate. 